\title{
A Logic Circuit Simulation for Finding Identical or Redundant Files using Counter and Register
}

\author{
${ }^{1}$ Lianly Rompis \\ ${ }^{1}$ Electrical Engineering Study Program, Faculty of Engineering, \\ Universitas Katolik De La Salle Manado; \\ Irompis@unikadelasalle.ac.id
}

\begin{abstract}
Computers and internet have become globally used nowadays and also part of the important facilities that could support information exchanges and cloud computing. People deals with texts, images, and videos processing, reaches out the specific goal of their works. It happens that due to much information and procedures, people will have many redundant files such as images or videos in their host computers or terminals, or maybe for some specific reasons people need to find data from big servers that surely have many files with same type and property because people accidentally put them there without knowing others also probably put the same ones. Using the basic concept of sequential logic circuit and electronic workbench 5.12 software, a logic circuit simulation consists of counter and register could be designed to show logically how to a computer or digital machine would interact to find redundant files, images or videos, or same files from many identical data from a server. The methods being used are study literature, analysis, design, and simulation. The output shows an expected result, a logic circuit simulation that could be applied on digital devices for finding identical or redundant files, or other related important process.
\end{abstract}

Keywords: Redundant Files, Identical Data, Redundant Data, Image and Video, Cloud Computing

\section{Introduction}

Big Data and Cloud Computing are the essential things recently related to Digital and Information Technologies. Everything is putted in the internet and data is the core of all the information people dealing with. However, have we ever imagined before how many data are being stored and how many data could possibly have the same size, properties, and type because it is being stored many times with different names by someone or being passed among people around the world? This probably will not become a great problem for big data and cloud computing in the future because of the unlimited capacity, but if we can manage those data or files, at least could support efficiency for data storage and server endurance. Using the basic concept of sequential circuit and Electronic Workbench 5.12 software utility, we can build and simulate a logic circuit consists of two main components, counter and register, which can be used to find identical or redundant data such as same images or same videos. It will then would be further sorted for re-selection or automatically deleted. 


\section{Methods}

Learning from several methodologies from $[7,8]$, the methodology being used for this research mainly to understand the basic concept of sequential logic circuit and combine the functions of counter and register, to derive a logic circuit simulation for finding redundant or identical images or videos.

\section{Basic Theories}

\subsection{Asynchronous Counter}

Asynchronous Counter is a type of sequential logic circuit functions for counting binary information, which all the input of all the flip-flop components are connected together to logic 1 (standard high dc voltage). The first clock is connected to a clock source, while the other clocks need to be connected to output $Q$ from previous flip-flop, as shown in Figure $1[1,2,3,4,5,6]$. The number of bit depends on number of flip-flop being used. For example, in Figure 1, to have a design output values in 4-bit length, the number of flip-flop that we used is 4 (four) also. The bit-sequences are given in Figure 2 [6].

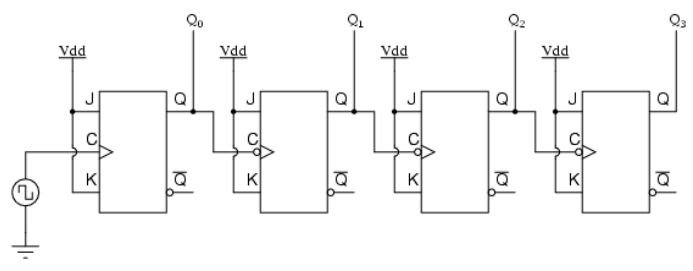

Figure 1. A four-bit asynchronous up counter

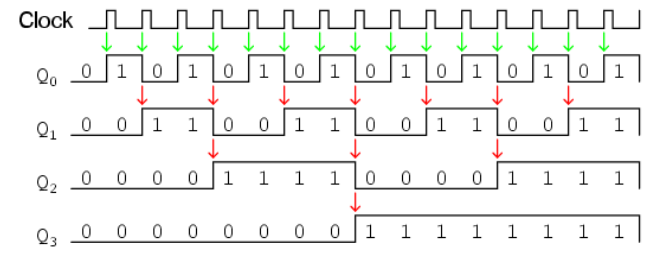

Figure 2. A four-bit asynchronous output waveform $\left(Q_{3} Q_{2} Q_{1} Q_{0}\right)$

\subsection{Shift Register}

Shift register is another type of sequential logic circuit, mainly for storing digital data. They are a group of flip-flops, usually D-FF, connected in a loop so that the output from one flip-flop becomes the input of the next flip-flop, and so on $[1,2,5]$. All the flip-flops are driven by a common clock, and all are set or reset simultaneously. This is shown in Figure 3.

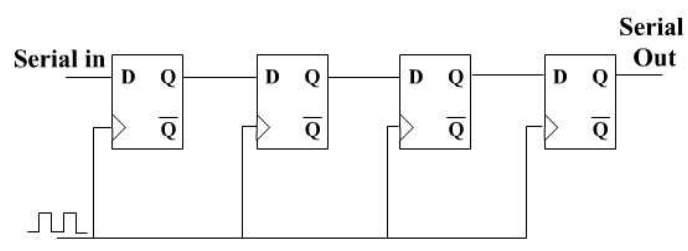

Figure 3. Right shift register

\subsection{RS-Flip Flop}

Flip-Flop is a basic component of combinational logic circuit and sequential logic circuit, mostly used in building counter and register circuits. The design for flip-flop comes from logic gate circuits. RS-Flip Flop is one of the main flip-flops that normally functions as a latch. It has an input of 2 lines and output of 2 lines as being referred in $[1,2,3,4,5]$.

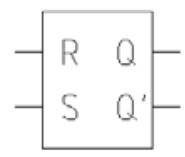

Figure 4. Schematic symbol of RS-FF

A schematic of RS-FF (Reset-Set Flip-Flop) is shown in Figure 4. The state table as the characteristic of it is given in Table 1. The output will not change if the inputs are zeros. If the Reset Input is set to logic 1 , the output will be zero, and the reverse, if the Set Input is set to logic 1, the output will be one. 
Table 1. Tuth table of an RS flip-flop

\begin{tabular}{|c|c|c|c|}
\hline \multicolumn{2}{|c|}{ INPUTS } & \multicolumn{2}{c|}{ OUTPUTS } \\
\hline R & S & Qn+1 & $\overline{\mathbf{Q n}+\mathbf{1}}$ \\
\hline \hline 0 & 0 & Qn & $\overline{\mathrm{Qn}}$ \\
\hline 0 & 1 & 0 & 1 \\
\hline 1 & 0 & 1 & 0 \\
\hline 1 & 1 & - & - \\
\hline
\end{tabular}

\subsection{XNOR Logic Gate}

Logic Gates are the basic components of digital logic circuit and the core parts of building a digital computer. One of the important logic gates is an XNOR logic gate. The output of this logic gate is 1 only if the number of logic 1 in inputs is even, as given in Table 2 . The schematic symbol is shown in Figure $5[1,2,3,4,5]$.

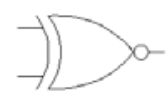

Figure 5. Schematic symbol of 2-input XNOR logic gate

Table 2. Tuth table of a 2-input XNOR logic gate

\begin{tabular}{|c|c|c|}
\hline \multicolumn{2}{|c|}{ INPUTS } & OUTPUT \\
\hline \hline 0 & 0 & 1 \\
\hline 0 & 1 & 0 \\
\hline 1 & 0 & 0 \\
\hline 1 & 1 & 1 \\
\hline
\end{tabular}

\section{Analysis and Design}

\subsection{Analysis}

Asynchronous counter functions as a counting circuit, starting from number 0 to number 15 . Let's assume the numbers referred as a unique number of files being stored. The files can be called and compared to a file being given as an input to the computer or digital device. In here, we use a 3-bit asynchronous up-counter for simple logic simulation, which ranges from 0 to 7 as shown in Figure 6. This counter is used to call an image or video file according to their unique number, respectively.

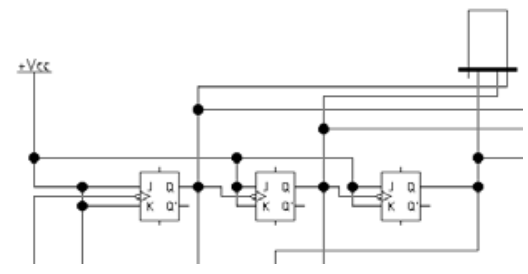

Figure 6. Asynchronous counter for basic simulation

All the files being called will then be compared one by one with the source file being input to the system or computer. Whenever the two compared files are match, the system will send the output and display it. So it will need a comparator for the task. For this logic simulation we can use XNOR gates because of its 'comparing' characteristic, given by Figure 7 . 


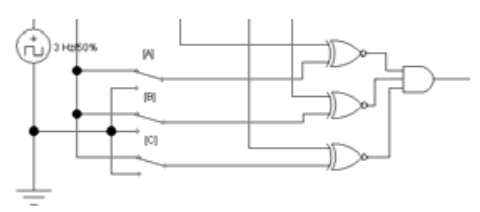

Figure 7. Logical inputs with comparator

The counter will keep count in a loop except we have a controller circuit to arrange the way it counts. That is why we need to add register to store and keep the file and display it on the output. Here we use D-FFs like the following one described in Figure 8.

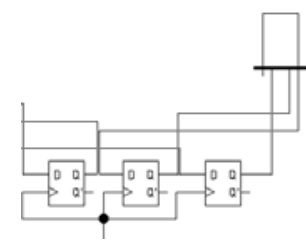

Figure 8. Shift register

\subsection{Design}

A computer has groups of counter and register that usually built for processing digital information in bits or bytes. All information is stored in registers with a unique number.

This logic circuit connection represents a simple way how actually data can be handled by a logical component known as counter and register. Their logical characteristics might be used as a basic concept for data processing and analysis, especially in organizing data. Figure 9 explains the part of computer architecture and Figure 10 gives the block diagram of further logic simulation that could be done.

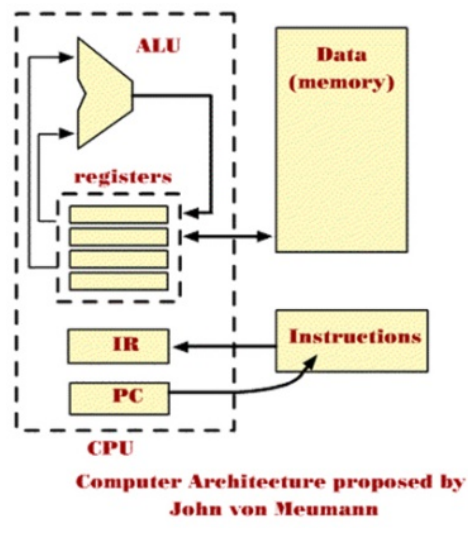

Figure 9. Computer architecture

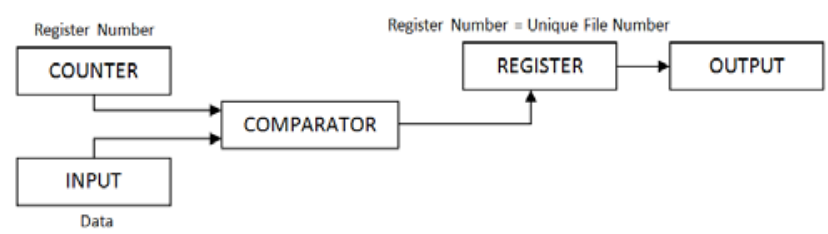

Figure 10. Block diagram for finding file

Based on the given analysis and each component characteristic, in this research counter, register, inputs, and comparator are connected together, as shown in Figure 11. 


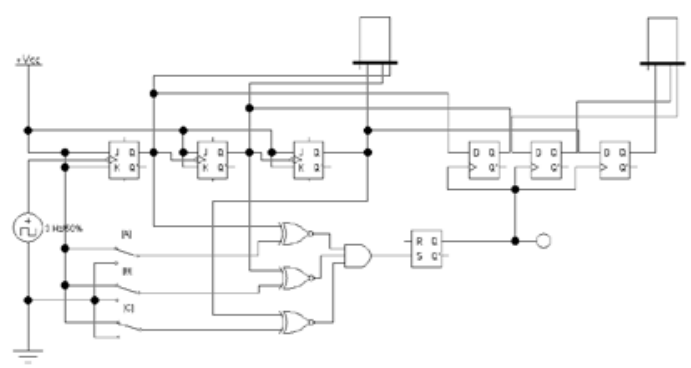

Figure 11. Basic logic circuit simulation with register and counter

The logical inputs will be compared with counting number, and if they have same unique logical number, the file being stored in register would be called and displayed. We can set up and do programming that would stop the counter or make it keeps counting and looking up for other same files.

\section{Simulation}

From the simulations using software Electronic Workbench 5.12, the designed logic circuit gives the expected outputs. In Figure 12, counter keeps count although same file already displayed.

(a)

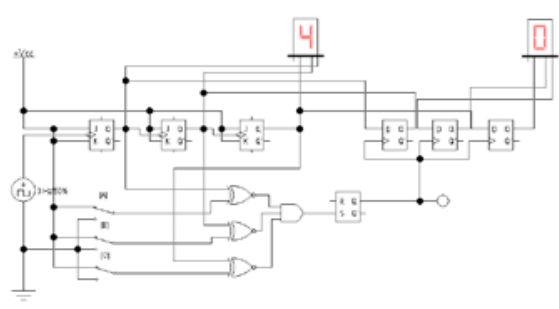

(b)

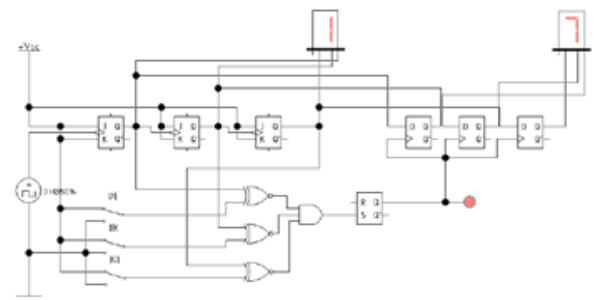

Figure 12. Simulation shows that same file will be displayed but counter keeps counting

Modifying the hardware circuit or program, we can stop the counter as shown in the following Figure 11. After the system detects the same file, counter will stop and register will show the right file on display. It can be started again and do comparison on the same file based on the inputs.

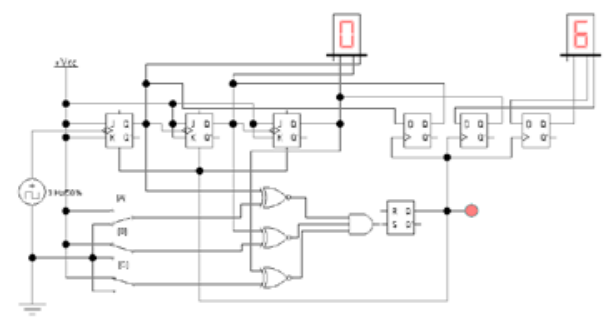

Figure 13. Simulation shows that counter will stop when system detects same file

Again modifying the hardware circuit or program, it happen that we can let the counter keeps counting and register will match and keep changing its file with the counter, as shown in Figure 12.

This is a kind like scan files based on the source file and probably can be used to detect redundant files. 
(a)

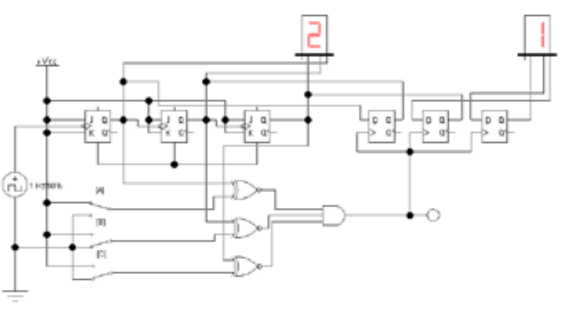

(b)

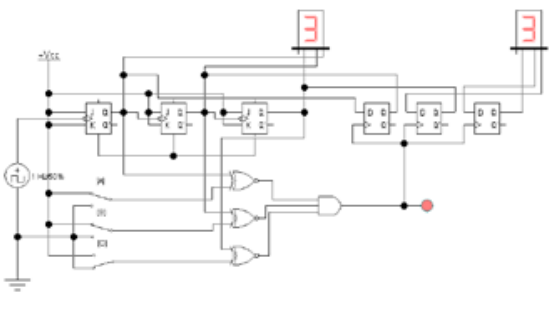

(d)

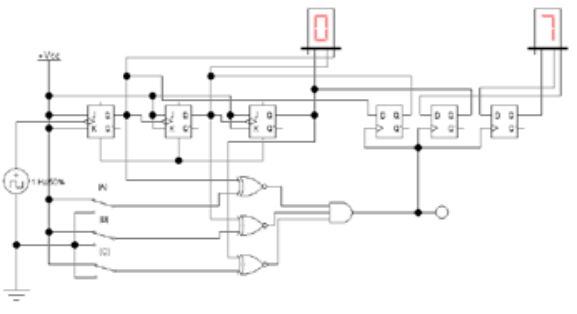

(c)

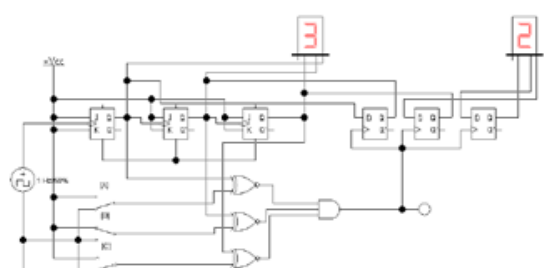

Figure 14. Simulation shows that register will do the comparison every time and display the same file

\section{Conclusion}

Using Counter and Register, we can build a logic circuit simulation for finding or detecting image or video files for data processing or data efficiency. This is only a basic concept and simple simulation that figures out more clearly about the functions of a counter and a register. The logic circuit simulation assumes that every file could be uniquely characterized in unique logical number (bits or bytes). Same file refers to a file that has a same size, type, properties, and content, although different in name. In can be used for further research development in hardware or software engineering to handle information more efficiently and help user to organize their files and data storage, by finding the same files or removing redundant files in case it is very important to have only one specific and unique file.

\section{REFERENCES}

[1]. Malvino, A., Elektronika Komputer Digital. Jakarta: Penerbit Erlangga, 1988.

[2]. Cavanagh, Digital Computer Arithmatic Design and Implementation. McGraw Hill, 1985.

[3]. Holdsworth, Digital Logic Design. Busterworth, 1982.

[4]. Tokheim, R., Prinsip-Prinsip Digital. Jakarta: Penerbit Erlangga, 1996.

[5]. Budiharto, W., Elektronika Digital dan Mikroprosesor. Yogyakarta: Penerbit ANDI, 2005.

[6]. All About Circuits, "Asynchronous Counters", All About Circuits.com, 2012.

Source: https://www.allaboutcircuits.com/textbook/digital/chpt-11/asynchronous-counters/

[7]. Sangadji, E. and Sopiah, Metodologi Penelitian: Pendekatan Praktis dalam Penelitian. Yogyakarta: Penerbit ANDI, 2010.

[8]. Semiawan, C.R. and Raco, J.R., Metode Penelitian Kualitatif: Jenis, Karakteristik, dan Keunggulannya. Jakarta: Penerbit Grasindo, 2010. 